\title{
O cotidiano em territórios quilombolas de Mato Grosso do Sul, Brasil: do isolamento às múltiplas (re)existências
}

\author{
The everyday life in quilombola territories in Mato Grosso do Sul, Brazil: from \\ isolation to multiple (re)existences
}

\section{La vida cotidiana en los territorios quilombolas en Mato Grosso do Sul, Brasil: del aislamiento a las múltiples (re)existencias}

\author{
Dyego de Oliveira Arruda ${ }^{1}$ \\ Milton Augusto Pasquotto Mariani² \\ Gabriel Luis Pereira Nolasco ${ }^{3}$ \\ Dayana de Oliveira Arruda ${ }^{2}$
}

\begin{abstract}
Resumo: O presente artigo objetiva problematizar elementos que caracterizam o cotidiano de territórios quilombolas localizados em Mato Grosso do Sul, no Centro-Oeste brasileiro. Parte-se da perspectiva de que as comunidades quilombolas representam espaços significativamente estigmatizados, nos quais os sujeitos aquilombados são vítimas de toda a sorte de manifestações de racismo e preconceito, em um arranjo de coisas no qual o Estado não consegue empreender, de modo efetivo, estratégias e políticas públicas que amparem as comunidades quilombolas e as pessoas que nelas residem. Como subterfúgio metodológico, a presente pesquisa valeu-se de uma abordagem qualitativa e crítica, na qual foram realizadas entrevistas e processos de observação participante em sete comunidades quilombolas localizadas em diferentes municípios de Mato Grosso do Sul. Em suma, percebeu-se que os territórios quilombolas são permeados por um cotidiano deveras dual: de um lado, tem-se uma realidade de isolamento e precariedade da vida; de outro, percebese um contexto de otimismo por parte dos quilombolas, que empreendem táticas de empoderamento, tentam valorizar a história e cultura do território, além do desejo de desenvolver atividades que dinamizem as comunidades. Sem pretender esgotar a temática, o presente artigo encerra-se conclamando para que as comunidades quilombolas sejam consideradas espaços potenciais e viáveis para a manifestação de formas de vida e de existência que rompem com a lógica homogeneizante e eurocêntrica.
\end{abstract}

Palavras-chave: comunidades quilombolas; território; estudos étnico-raciais; racismo.

Abstract: This article aims to problematize elements that characterize the everyday life of quilombola territories located in the State of Mato Grosso do Sul, in the Brazilian Midwest. In summary, we start from the perspective that quilombola communities represent significantly stigmatized spaces, in which the subjects who reside in them are victims of manifestations of racism and prejudice, in such a way that the State apparatus is unable to undertake strategies and public policies that support quilombola communities and the people who live in them. As a methodological subterfuge, this research used a qualitative and critical approach, in which interviews and participant observation processes were carried out in seven quilombola communities located in different municipalities in the State of Mato Grosso do Sul, Brazil. We noticed that quilombola territories are permeated by a very dual daily life: on the one hand, there is a reality of isolation and precariousness in life; on the other hand, there is a context of optimism by the quilombola communities, who undertake empowerment tactics, trying to value the history and culture of the territory, in addition to the desire to develop activities that make communities more dynamic. Without intending to exhaust the theme, this article ends by calling for quilombola communities to be considered potential and viable spaces for the manifestation of forms of life and existence that break with the homogenizing and Eurocentric logic. Keywords: quilombola communities; territory; ethnic-racial studies; racism.

Resumen: Este artículo tiene como objetivo problematizar elementos que caracterizan la vida cotidiana de los territorios quilombolas ubicados en Mato Grosso do Sul, en el Centro-Oeste brasileño. En resumen,

\footnotetext{
${ }^{1}$ Centro Federal de Educação Tecnológica Celso Suckow da Fonseca (CEFET/RJ), Valença e Rio de Janeiro, Rio de Janeiro, Brasil.

2 Universidade Federal de Mato Grosso do Sul (UFMS), Campo Grande, Mato Grosso do Sul, Brasil.

${ }^{3}$ Universidade Católica Dom Bosco (UCDB), Campo Grande, Mato Grosso do Sul, Brasil.
} 
partimos de la perspectiva de que las comunidades quilombolas representan espacios significativamente estigmatizados, en los cuales los sujetos son víctimas de manifestaciones de racismo y prejuicio, de tal manera que el Estado no es capaz de emprender políticas públicas y estrategias efectivas que apoyen a las comunidades y a las personas de los territorios. Como subterfugio metodológico, esta investigación utilizó un enfoque cualitativo y crítico, en el que se llevaron a cabo entrevistas y procesos de observación participante en siete comunidades quilombolas ubicadas en diferentes municipios de Mato Grosso do Sul, Brasil. En síntesis, se notó que los territorios quilombolas están impregnados de una vida diaria muy dual: por un lado, existe una realidad de aislamiento y precariedad en la vida; por otro lado, existe un contexto de optimismo por parte de los quilombolas, quienes emprenden tácticas de empoderamiento, tratando de valorar la historia y la cultura del territorio, además del deseo de desarrollar actividades que hagan que las comunidades sean más dinámicas. Sin pretender agotar el tema, este artículo termina llamando a las comunidades quilombolas a ser consideradas espacios potenciales y viables para la manifestación de formas de vida y existencia que rompan con la lógica homogenizante y eurocéntrica.

Palabras clave: comunidades quilombolas; territorio; estudios étnico-raciales; racismo

\section{INTRODUÇÃO}

Os territórios quilombolas são espaços ocupados por pessoas que, ao longo do processo histórico de constituição das sociedades contemporâneas, foram exploradas, excluídas e subalternizadas, sobretudo em países com passado escravagista e colonial, tais como o Brasil (VALENTIM; TRINDADE, 2011).

Ao tratar da historiografia e etimologia do termo quilombo, Munanga (1996) pontua que os territórios quilombolas brasileiros perfazem uma réplica dos quilombos africanos: são espaços em que as pessoas negras escravizadas e seus descendentes, ao fugirem das senzalas e dos grilhões da exploração nas plantations, procuravam algum tipo de proteção contra todo um sistema político e econômico que considerava o corpo negro como mera mercadoria, passível de toda a sorte dos mais variados usos e abusos.

No Brasil, o território quilombola que melhor sinalizou o ideário da luta e resistência contra a escravização dos negros foi o Quilombo dos Palmares, cuja origem remonta ao final do século XVI, na região da Serra da Barriga, atual Estado de Alagoas. Em um período em que a escravização de pessoas negras para o trabalho forçado constituía a base da economia do Brasil colonial, os negros aquilombados em Palmares desenvolveram laços de sociabilidade que Ihes permitiram resistir até o início do século XVIII contra todas as investidas que objetivavam aniquilar aquele território de sociabilidade entre negros/as (FUNARI; CARVALHO, 2005).

O exemplo de resistência e o contexto histórico em que surgiu Palmares fez com que as pesquisas que tratam dos quilombos brasileiros tenham considerado esses espaços enquanto territórios originados exclusivamente pela fuga de negros escravizados que, na maioria das circunstâncias, compunham agrupamentos homogêneos, com pessoas que nutriam laços de proximidade e parentesco muito consolidados e que comungavam de uma mesma cultura (FUNARI, 2001).

De todo modo, Schmitt, Turatti e Carvalho (2002) sugerem que a supracitada perspectiva deve ser relativizada nos estudos contemporâneos. No entender dos autores em tela, os agrupamentos quilombolas cada vez mais revelam-se como espaços plurais em que, a despeito da identificação com a cor da pele e/ou com outro marcador social da diferença, coexistem grupos heterogêneos, com estilos de vida e especificidades socioculturais muito peculiares. Nesse ínterim, Allen (2000) pondera que até mesmo no lendário caso do Quilombo de Palmares coexistiam agrupamentos de negros, mestiços, indígenas, além de um diverso contingente de 
pessoas que, a partir de laços de sociabilidade e união, encontravam em Palmares uma verdadeira trincheira para se opor às formas de opressão características do Brasil colonial.

Contemporaneamente, Leite (2010) salienta que os quilombos constituem espaços significativamente estigmatizados: reúnem predominantemente pessoas negras e seus descendentes que vivem de forma precária, com baixos níveis de renda, em locais degradados e/ ou de difícil acesso, e com uma quase inexistente rede de provisão de serviços públicos (tais como água encanada, luz elétrica, escolas, creches e afins). Adicione-se ainda a constatação de que, para além da vida precária, os quilombolas ainda são vítimas de toda a sorte de manifestações de racismo, inclusive por parte do próprio Estado, que nem sequer reconhece plenamente a dívida histórica para com o povo negro e seus descendentes (SOUZAS, 2015).

Quanto à relação do Estado brasileiro com as comunidades quilombolas, deve-se salientar que o aparato estatal e público, sobretudo na época do Brasil colônia (século XVI até XVIII), era agente ativo nos esforços de perseguição e extermínio dos agrupamentos quilombolas (LEITE, 2010). Contemporaneamente, mesmo com o surgimento de políticas públicas que almejam - ao menos em tese - amparar as comunidades quilombolas, titulando as terras que essas pessoas tradicionalmente habitam e estimulando a melhora da qualidade de vida das comunidades, ainda assim vale destacar que essas iniciativas são muito fragmentadas e pouco contundentes, numa dinâmica em que a omissão do Estado em efetivamente amparar os grupos quilombolas acaba por reforçar ainda mais o contexto de precariedade sob o qual se encontram esses sujeitos (FIGUEIREDO, 2015; ARRUDA; GONÇALVES, 2020).

Não obstante Nascimento (2019), além de Almeida e Mesquita (2019), a despeito de reconhecerem a precariedade da vida nos quilombos, provocam-nos para uma descolonização do pensamento sobre essas comunidades. Nesse ínterim, Catherine Walsh (2019) nos lembra que insistir na descolonização implica em aderir a novas formas de produção de conhecimento, marcadas pelo tensionamento dos valores coloniais e hegemônicos, numa dinâmica em que tal perspectiva inevitavelmente nos descortina possibilidades de insurgências, pautadas por valores e saberes que rompem com a hegemonia eurocêntrica para se pensar a ciência, o conhecimento e a (re)produção da vida nos mais variados agrupamentos sociais.

Desse modo, partindo de um prisma decolonial para se pensar os quilombos, entendemos que reside no cotidiano das próprias comunidades os laços de sociabilidade, criatividade e resistência que permitirão - mesmo com a omissão do aparato de Estado, das políticas públicas e até da sociedade civil organizada - um caminho de efetiva emancipação das comunidades.

Descolonizar o pensamento sobre os territórios quilombolas implica reconhecer o valor da resistência histórica dessas comunidades, a potencialidade das histórias e da tradição oral transmitida entre gerações de negros(as) aquilombados(as), o valor da terra e a íntima relação que as comunidades nutrem com o território, além da comunhão e solidariedade entre os quilombolas, que constantemente ressignificam a aparente invisibilização dos territórios e fazem das comunidades um repertório de múltiplas (re)existências possíveis (ALMEIDA; MESQUITA, 2019).

Porém qual é o cotidiano das comunidades quilombolas, contemporaneamente? Em um estado tal como Mato Grosso do Sul - eminentemente agrário, em que predomina a lógica mercantil e capitalista do agronegócio -, como as comunidades quilombolas vivem, cotidianamente, a contradição entre o aparente isolamento do território e as múltiplas (re) existências possíveis? 
Assim sendo, tendo como base as supracitadas questões, o presente estudo tem o objetivo de problematizar, a partir de diálogos com os sujeitos aquilombados, a realidade de territórios quilombolas em Mato Grosso do Sul, desnudando elementos que caracterizam o cotidiano dessas comunidades.

Deve-se destacar, por ser oportuno, que o artigo parte de um prisma epistemológico em que, a despeito da ciência quanto ao contexto de precariedade material e isolamento inerente às comunidades quilombolas - conforme revelaram Leite (2010) e Souzas (2015), citadas nesta introdução -, há uma preocupação em entender também os quilombos enquanto territórios cercados de significativas potencialidades, em que os grupos historicamente subalternizados podem construir, por si próprios, múltiplas manifestações de agenciamentos sobre suas vidas, tendo como propósito a construção de caminhos que levem a possibilidades de emancipação das comunidades e dos sujeitos que nela residem (NASCIMENTO, 2019).

Compreender as múltiplas (re)existências que surgem da própria realidade dos territórios quilombolas implica considerar os sujeitos aquilombados enquanto produtores de novas possibilidades e narrativas que, idealmente, impliquem processos de empoderamento e melhoria da qualidade de vida nos territórios quilombolas, de modo a se valorizar a história, a cultura e o modo de vida dos indivíduos que residem nessas comunidades, rompendo com o contexto de precariedade que atravessa os territórios em questão.

O foco das reflexões deste estudo nos quilombos de Mato Grosso do Sul decorre da invisibilização desses grupos, conforme sugerem Urquiza e Santos (2017). Ainda segundo os autores, o contexto cultural e socioeconômico sul-mato-grossense implica constantes pressões, principalmente sobre os territórios historicamente ocupados pelos quilombolas, em um cenário em que são essenciais os esforços de subversão crítica, tendo como escopo compreender, a partir de lentes teórico-epistemológicas decoloniais, as múltiplas experiências de resistência e emancipação protagonizadas por esses sujeitos.

\section{PERCURSOS METODOLÓGICOS DA PESQUISA}

Para problematizarmos as características do cotidiano de comunidades quilombolas de Mato Grosso do Sul, adotamos a perspectiva qualitativa durante nossa inserção no campo da pesquisa, tendo como premissa o diálogo, de modo crítico e não hegemônico, com os detalhes do modo de vida e, portanto, das práticas cotidianas experienciadas nas comunidades.

Ao longo dos processos de coleta de dados empíricos, procuramos estabelecer contato direto com as comunidades, primando pelo respeito aos costumes e modos de vida dos territórios visitados. Os processos de obtenção de dados para o estudo decorreram de entrevistas com os sujeitos aquilombados, tendo como escopo assimilar elementos do cotidiano das comunidades a partir das narrativas dos próprios sujeitos que residem nesses territórios. Além disso, foram empreendidos processos de observação participante, numa dinâmica em que tal técnica possibilitou o estabelecimento de vínculos entre os pesquisadores e a realidade investigada.

A nossa pretensão, ao longo das atividades de campo, foi nos aproximarmos ao máximo das realidades e percepções decorrentes do lugar de fala das pessoas, ou seja: a intenção foi refletir a partir do modo como as próprias pessoas que residem nas comunidades quilombolas leem elementos do cotidiano nos territórios que ocupam.

Ribeiro (2019), ao discutir o conceito de lugar de fala, sugere que a produção de conhecimento, contemporaneamente, deve despir-se de seu caráter colonialista e, nesse sentido, 
compreender a realidade a partir do olhar e do modo de vida dos próprios sujeitos de pesquisa, não raro com base em epistemologias e formas próprias de produção de conhecimento.

Nas interações com os quilombos pesquisados, no período de fevereiro até setembro de 2019, adotamos o expediente de, primeiramente, contatar as lideranças constituídas nos territórios - normalmente, as(os) presidentas(es) das associações de moradores das comunidades -, de tal modo que, a partir dos diálogos prévios com as lideranças, foi possível ganhar confiança e credibilidade por parte das comunidades, para que, desse modo, fosse possível também o diálogo com outros sujeitos dos territórios.

Em campo, as nossas estratégias de pesquisa passaram pela observação atenta de detalhes da comunidade - tais como as condições físicas e estruturais das moradias, as formas de acesso às comunidades, a beleza cênica dos territórios, as atividades produtivas empreendidas, além dos espaços de sociabilidade e de culto. Ademais, nas entrevistas empreendidas com os quilombolas, tentamos captar, a partir da fala livre desses sujeitos, características do cotidiano nesses territórios. Em suma, as entrevistas foram estruturadas a partir de questões norteadoras que objetivavam estimular a fala dos sujeitos da pesquisa, tendo como meta compreender os seguintes aspectos: percursos históricos que determinaram o surgimento do agrupamento quilombola; detalhes do dia a dia nas comunidades; sentidos e significados inerentes à vida no território; caminhos a partir dos quais a comunidade acessa (ou não) as políticas públicas e o próprio aparato de Estado; manifestações de racismo e preconceito que recaem sobre a comunidade; e características que tornam a vida nos quilombos possível, agradável e desejável.

Vale dizer que os processos empíricos de coleta de dados foram consentidos tanto pelas lideranças constituídas nas comunidades (que assinaram um Termo de Consentimento Livre e Esclarecido, em que foram especificados todos os detalhes da pesquisa) quanto pelas demais pessoas que estabeleceram diálogos com a equipe de pesquisa. Sempre que previamente autorizado, as entrevistas foram gravadas, tendo como propósito o fiel registro do conteúdo das falas das pessoas. Ademais, optamos por realizar registros fotográficos nas comunidades, também como subterfúgio para a coleta e o armazenamento de informações sobre os territórios (registros fotográficos, estes também consentidos pelas comunidades).

Ressalte-se que, de posse das imagens fotográficas e das transcrições dos diálogos com os sujeitos dos territórios quilombolas, conduzimos uma análise de conteúdo categorial, nos moldes do que sugere Bardin (2011), ou seja: a partir de várias leituras do teor das transcrições dos diálogos, empreendemos o esforço de comparar o conteúdo dos diálogos com as imagens fotográficas que foram feitas, sempre com o escopo de categorizar o conteúdo das informações que foram provenientes das nossas interações no âmbito do campo de pesquisa.

Os territórios quilombolas efetivamente pesquisados constam no Quadro 1, que, além de especificar as localidades (municípios) em que essas comunidades se situam, aponta características gerais dos territórios quilombolas que fizeram parte da pesquisa. 
Quadro 1 - Comunidades quilombolas contempladas no estudo

\begin{tabular}{|c|c|l|}
\hline Nome do território & Cidade & \multicolumn{1}{|c|}{ Características gerais do território } \\
\hline $\begin{array}{c}\text { Comunidade } \\
\text { Quilombola } \\
\text { Chácara Buriti }\end{array}$ & $\begin{array}{c}\text { Campo Grande, que } \\
\text { é capital de Mato } \\
\text { Grosso do Sul (MS) }\end{array}$ & $\begin{array}{l}\text { Trata-se de uma comunidade localizada no perímetro } \\
\text { rural, que desenvolve atividades ligadas à agricultura } \\
\text { familiar. Reconhecida legalmente, como remanescente } \\
\text { de quilombo, desde 2005. Possui aproximadamente 32 } \\
\text { famílias. }\end{array}$ \\
\hline $\begin{array}{c}\text { Comunidade } \\
\text { Quilombola Furnas } \\
\text { do Dionísio }\end{array}$ & $\begin{array}{c}\text { Jaraguari, cidade } \\
\text { pouco mais de } 50 \text { km } \\
\text { distante de Campo } \\
\text { Grande }\end{array}$ & $\begin{array}{l}\text { Localiza-se no perímetro rural e empreende atividades } \\
\text { ligadas à agricultura familiar e ao turismo de aventura; } \\
\text { conta com 100 famílias. Reconhecida legalmente, como } \\
\text { remanescente de quilombo, desde 2005. }\end{array}$ \\
\hline $\begin{array}{c}\text { Comunidade } \\
\text { Benedilombola de São }\end{array}$ & Campo Grande & $\begin{array}{l}\text { Localiza-se no perímetro urbano de Campo Grande, } \\
\text { próximo à região central da cidade, em um local em que } \\
\text { residem aproximadamente 130 famílias. Comunidade } \\
\text { quilombola legalmente reconhecida, desde 2008. }\end{array}$ \\
\hline $\begin{array}{c}\text { Comunidade } \\
\text { Quilombola de }\end{array}$ & Aquidauana & $\begin{array}{l}\text { Localiza-se no perímetro rural e desenvolve atividades } \\
\text { de agricultura familiar e turismo no espaço rural; possui } \\
\text { aproximadamente 20 famílias. Reconhecida legalmente, } \\
\text { como território quilombola, desde 2007. }\end{array}$ \\
\hline $\begin{array}{c}\text { Comunidade } \\
\text { Quilombola } \\
\text { Campos Correa }\end{array}$ & $\begin{array}{c}\text { Corumbá, um rele- } \\
\text { vante destino turístico, } \\
\text { considerado a "capi- } \\
\text { tal" do Pantanal de MS }\end{array}$ & $\begin{array}{l}\text { Localiza-se no perímetro urbano e empreende } \\
\text { atividades ligadas à pesca; possui aproximadamente } \\
\text { 20 famílias. Reconhecida legalmente, como quilombo, } \\
\text { desde 2013. }\end{array}$ \\
\hline $\begin{array}{c}\text { Comunidade } \\
\text { Quilombola Família } \\
\text { Osório }\end{array}$ & Corumbá & $\begin{array}{l}\text { Localiza-se no perímetro urbano e empreende } \\
\text { atividades ligadas à pesca; possui 25 famílias. } \\
\text { Reconhecida legalmente, como quilombo, desde 2010. }\end{array}$ \\
\hline $\begin{array}{c}\text { Comunidade } \\
\text { Theodora }\end{array}$ & $\begin{array}{l}\text { Trata-se de uma comunidade de terreiro, ligada à } \\
\text { Umbanda, e localiza-se no perímetro urbano de } \\
\text { Corumbá; possui aproximadamente 22 famílias. } \\
\text { Reconhecida legalmente, como quilombo, desde 2011. }\end{array}$ \\
\hline
\end{tabular}

Fonte: Elaborado pelos autores, 2020.

Ao todo, foram realizadas sete entrevistas, uma em cada território que consta no Quadro 1. De uma maneira geral, a nossa pretensão foi realizar entrevistas individualizadas com as pessoas apontadas, no território, como as mais experientes e capazes de fornecer detalhes acerca da história e das características gerais do cotidiano nas comunidades. Vale apontar, por ser oportuno, que nas comunidades de Campos Correa e Família Osório, ambas em Corumbá, a comunidade reuniu-se para interagir com os pesquisadores, numa dinâmica em que, nesses territórios, as entrevistas assumiram um caráter de diálogo coletivo. De todo modo, entendemos que tal arranjo de coisas não implicou prejuízo algum ao esforço de coleta de dados nesses territórios, uma vez que todas as questões essenciais para o estudo foram respondidas pela comunidade, ainda que de forma coletiva e dialogada.

O esforço de interação no escopo das entrevistas, com as pessoas mais experientes das comunidades, decorreu da crença, por parte dos pesquisadores, de que esses indivíduos são aqueles que conhecem profundamente os detalhes da vivência na comunidade, além da própria trajetória histórica dos quilombos. Como forma de resguardar o anonimato das pessoas que participaram das entrevistas, optamos por não identificar nominalmente esses sujeitos, ao longo das reflexões conduzidas neste artigo. 
É importante destacar que a presença dos pesquisadores nos territórios não ocorreu meramente na circunstância em que as entrevistas foram realizadas. No período em que a pesquisa foi conduzida, de fevereiro até setembro de 2019, os pesquisadores estiveram em outras oportunidades nos territórios quilombolas, seja para contatar as lideranças e pedir a devida autorização para a pesquisa, seja para visitar as comunidades, de modo a ganhar, paulatinamente, a confiança dos sujeitos participantes desta investigação. Em todas as oportunidades nas quais os pesquisadores estiveram nos territórios, sempre em duplas, ocorreram processos de observação participante, ainda que o escopo e o protocolo norteador do estudo estivessem em construção. Sempre após as visitas aos territórios, os pesquisadores reuniam-se, de modo a socializar e sistematizar as percepções decorrentes das interações estabelecidas no campo da pesquisa.

Todos os territórios contemplados no estudo foram selecionados em função da disponibilidade das comunidades em receber a equipe de pesquisa. Ademais, vale frisar que todos os territórios visitados são reconhecidos como comunidades quilombolas pela Fundação Cultural Palmares, autarquia atualmente vinculada à Secretaria Especial da Cultura do Governo Federal, que possui a obrigação de identificar, reconhecer, delimitar, demarcar e titular os territórios quilombolas, conforme disposições do Decreto n. 4.887, de 20 de novembro de 2003 (BRASIL, 2003). De todo modo, nenhuma das comunidades que constam no Quadro 1 possuem os processos de demarcação e titulação de suas terras efetivamente finalizados.

\section{ASPECTOS DA REALIDADE NAS COMUNIDADES QUILOMBOLAS}

Muito embora seja comum a crença de que os territórios quilombolas são compostos majoritariamente por descendentes de negros outrora escravizados, percebemos, ao dialogar com as comunidades sul-mato-grossenses pesquisadas, que não é corriqueiro esse tipo de consciência - a despeito de uma ascendência não raro ligada aos negros que foram escravizados, constatamos que as pessoas que atualmente residem nos territórios quilombolas não verbalizam, de modo pleno e "natural", esse tipo de percepção e de história.

Não obstante deve-se salientar que os quilombolas reconhecem elementos de sua própria negritude, ligados a uma mesma ancestralidade negra - percebemos que há menções recorrentes à cor da pele como aspecto fundante e característico das comunidades. Vale frisar que os elementos da negritude comungados por boa parte dos quilombolas, por um lado, fazem com que tais sujeitos sejam vítimas de manifestações de racismo e preconceito; porém, sob outra perspectiva, a ancestralidade negra impele com que a comunidade seja foco de novos laços de sociabilidade e de comunhão, que permitem com que a vida nos quilombos seja algo possível, viável e suscetível a novas (re)existências.

Urquiza e Santos (2017), em um estudo de viés historiográfico e documental, pontuam que as primeiras comunidades quilombolas no atual Estado de Mato Grosso do Sul surgiram no final do século XIX, muito em função de movimentos migratórios de famílias negras, a maioria já liberta, oriundas do sul de Minas Gerais, de Goiás e até da Bahia. Ainda segundo os autores, as famílias negras migrantes que se estabeleceram nos territórios em que, atualmente, estão as comunidades quilombolas sul-mato-grossenses nutriam uma relação muito particular com a terra e tinham por hábito a produção agrícola em pequena escala, para subsistência.

Contemporaneamente, percebe-se que as comunidades quilombolas de Mato Grosso do Sul são compostas pelos descendentes dos fundadores de tais agrupamentos, além de um conjunto de pessoas, tais como cônjuges, filhos, primos e netos, as quais foram, paulatinamente, 
incorporadas à comunidade. Deve-se frisar que o cotidiano nos territórios quilombolas é cercado de desafios e potencialidades, conforme discutiremos de modo mais detalhado nos tópicos que seguem.

\section{A REALIDADE DE ISOLAMENTO DAS COMUNIDADES}

Ao conduzirmos as nossas primeiras visitas aos territórios quilombolas sul-mato-grossenses que participaram desta pesquisa, ficou evidenciado o contexto de significativo isolamento por parte das comunidades, que, de uma maneira geral, são colocadas à margem das políticas públicas e dos próprios ciclos de crescimento e desenvolvimento socioeconômicos sustentáveis.

Tal situação de isolamento, que se manifesta à revelia do próprio desejo dos quilombolas, decorre principalmente dos seguintes aspectos: (a) do abandono por parte do Estado, que não faz com que as políticas públicas alcancem as comunidades de modo efetivo, melhorando a qualidade de vida nesses territórios; (b) do acesso precário, que é evidente mesmo nos territórios que se localizam no perímetro urbano dos municípios sul-mato-grossenses; (c) da pressão pela expropriação dos quilombolas do território, numa dinâmica em que o isolamento, nesse aspecto, reveste-se de um caráter funcional, que objetiva tornar inviável a vida nos quilombos, fazendo com que esses sujeitos deixem, por si próprios, seus territórios historicamente ocupados; e (d) das múltiplas manifestações de racismo contra os quilombolas, as quais pretendem desumanizar, estigmatizar e até exterminar, física e socialmente, esses indivíduos.

Fanon (2008) nos dá pistas de que o isolamento é algo inerente à condição de vida do negro, sobretudo após o período colonial, em que os corpos negros foram desumanizados e tratados como mercadoria. Segundo o autor em tela, o isolamento do negro perfaz algo constantemente reiterado pela ideologia da branquitude, que toma os corpos brancos como ideário de beleza, de ética e de altivez, estigmatizando, por conseguinte, o corpo negro como a personificação da feiura e de qualquer tipo de comportamento desviante.

$\mathrm{O}$ isolamento dos sujeitos negros, de uma maneira geral, manifesta-se de duas formas (FANON, 2008; MBEMBE, 2018): (a) pode ser eminentemente físico, em um arranjo de coisas no qual os negros são circunscritos em espaços delimitados, não raro completamente fechados, murados e/ou cercados - os processos de favelização, guetificação e aprisionamento dos corpos negros, por exemplo, possuem esse princípio; e (b) pode manifestar-se de forma simbólica, que é o caso em que se nega afeto e humanidade aos negros, estigmatizando a sua história e silenciando qualquer possibilidade de os indivíduos em questão reivindicarem as demandas que Ihes são importantes.

É paradigmático constatar que o próprio Estado é agente ativo nos processos de isolamento dos territórios quilombolas investigados. A Comunidade Quilombola de Campos Correa, por exemplo, a despeito de localizar-se no perímetro urbano, muito próximo da região central da cidade de Corumbá, nem sequer possui água encanada e luz elétrica - de uma maneira geral, a comunidade acessa esses itens básicos por intermédio de ligações clandestinas, chamadas de "gatos" pelos moradores do território. Ao serem questionados acerca do motivo pelo qual não há água encanada e luz elétrica regularmente instalados na comunidade, os quilombolas nos relataram que as próprias autarquias públicas do município se recusam a providenciar esses itens, sob o argumento de que os moradores não possuem a efetiva titulação da área em que residem - vale lembrar que a comunidade sob análise, assim como os demais quilombos 
sul-mato-grossenses visitados, muito embora sejam reconhecidos enquanto territórios quilombolas pela Fundação Cultural Palmares, não possuem a plena regularização fundiária e, portanto, a efetiva titulação de seus territórios. Constatamos, ao longo da pesquisa, que o processo de regularização fundiária e titulação dos quilombos encontra-se em curso no Instituto Nacional de Colonização e Reforma Agrária, responsável por conduzir estudos antropológicos nas comunidades, etapa que é importante nos ritos que podem determinar a regularização fundiária e titulação dos territórios.

Sendo assim, nota-se que a falta de coordenação entre as próprias políticas públicas - de um lado, a que prevê o processo de regularização fundiária dos territórios quilombolas e, de outro, a que oferece os itens básicos aos cidadãos, tais como água e luz - impele os quilombolas a viverem em uma condição de significativa precariedade, o que, no escopo deste estudo, é entendido como um cenário que reforça o isolamento das comunidades, numa dinâmica em que os quilombolas são colocados à margem de uma concepção plena de cidadania.

Uma observação desatenta, e até mesmo racista, poderia sugerir que os "gatos" nos territórios implicariam acesso fácil e gratuito à água e à luz. De todo modo, essa não foi a realidade constatada. Os próprios moradores demandam o acesso legal e regular a esses itens, sinalizando que desejam, mesmo diante de todas as dificuldades materiais sob as quais vivem, "Pagar pela água e pela luz, que é o que todo mundo faz", conforme se constatou em um dos relatos com os sujeitos da presente pesquisa. Desse modo, a demanda por água encanada e luz elétrica perfaz um desejo, à ótica da comunidade, de integração à sociedade, ressignificando um contexto de isolamento por eles mesmos percebido.

Quanto ao acesso físico às comunidades, percebemos que as vias que permitem com que se chegue até os territórios são significativamente precárias. No caso dos quilombos que se localizam no perímetro rural, essa dificuldade de acesso é agravada, principalmente, porque as rodovias vicinais não são pavimentadas e muitas delas carecem de um mínimo de conservação. Verificamos, por exemplo, no caso da Comunidade Quilombola de Furnas dos Baianos, localizada no município de Aquidauana, que os próprios moradores empreenderam esforços para tapar alguns buracos da estrada com entulhos, facilitando o acesso ao território, que não raro recebe a visita de turistas interessados em atividades de aventura, tais como caminhadas, trilhas e afins, que ocorrem no interior da comunidade em função das formações geológicas e geomorfológicas do território, as quais são propícias para as modalidades de turismo de aventura.

Não obstante chama atenção o fato de que, mesmo nos territórios que se localizam no perímetro urbano dos municípios, o acesso físico à comunidade é dificultado. Na Figura 1 abaixo, é possível observar detalhes do único acesso à comunidade de Campos Correa, em Corumbá: o muro alto, na imagem à esquerda, representa os fundos de uma casa, potencialmente habitada por moradores de alto poder aquisitivo; contíguo ao matagal, ainda na imagem à esquerda, há uma área de barranco e, logo na sequência, encontra-se o Rio Paraguai (conforme é possível observar na imagem à direita). De uma maneira geral, o único acesso que a comunidade possui é o pequeno corredor, chamado pelos moradores de "trieiro", na imagem à esquerda. Vale ressaltar que, nos diálogos com a comunidade em análise, percebemos que é conflituosa a relação dos quilombolas com os proprietários da referida casa de alto padrão: os quilombolas alegam que, além de dificultar o acesso e evitar qualquer forma de diálogo mais franco, os proprietários da casa em tela invadiram - segundo os sujeitos com os quais dialogamos - uma parte da área que é de direito da comunidade. 
Figura 1 - Detalhes do acesso à Comunidade Quilombola de Campos Correa
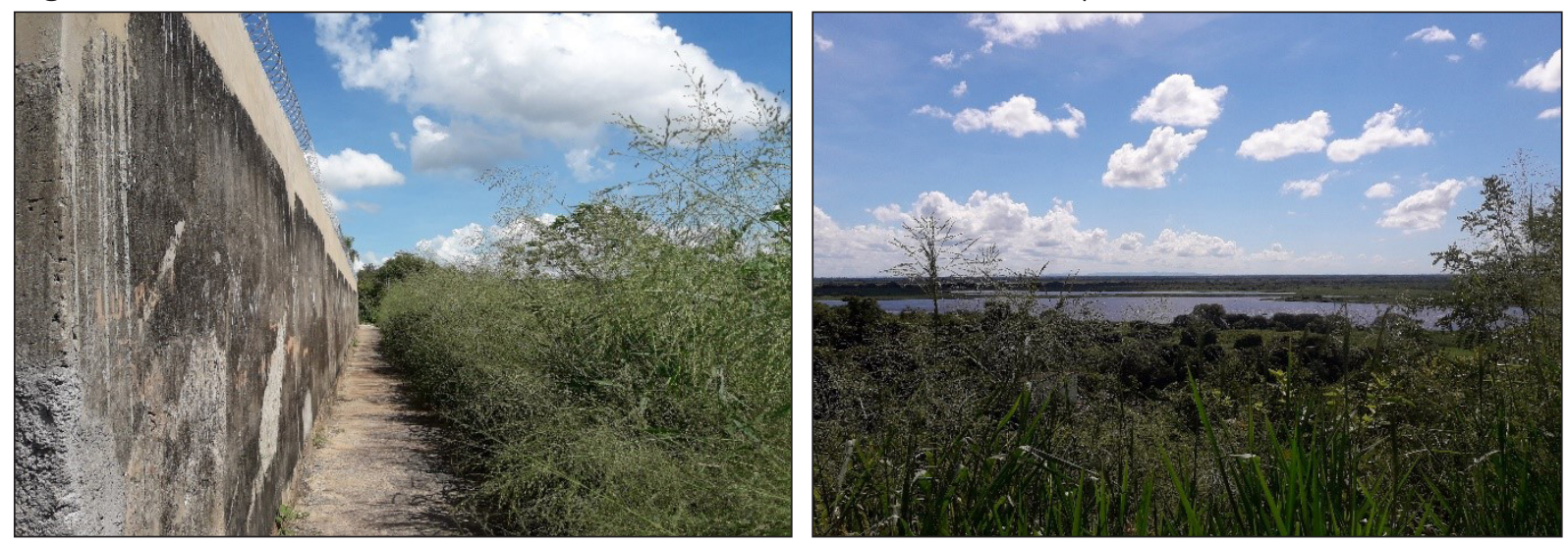

Fonte: Arquivo dos autores, 2020.

Ainda sobre a moradia de alto padrão que circunda a Comunidade Quilombola de Campos Correa, constatamos que a casa em questão, além de possuir muros demasiadamente altos (que revelam uma atitude racista, conforme analisaremos com mais detalhes adiante), apresenta uma espécie de deck, ainda mais alto do que os muros da residência, numa dinâmica em que há a possibilidade de que, do interior da residência, se vislumbre toda a paisagem da planície pantaneira formada pelo Rio Paraguai, que é um ativo importante, o qual fomenta processos de especulação imobiliária no município em análise, uma vez que a paisagem da planície pantaneira é um "produto" altamente demandado por pessoas que dispõem de poderio econômico na localidade.

Nesse ínterim, considerando o relato acima descrito, há um evidente processo de pressão sobre o território da comunidade de Campos Correa, assim como sobre os territórios de outras comunidades pesquisadas que possuem considerável beleza cênica. Pareceu-nos que a pressão sobre os quilombos, isolando as comunidades e tornando precária a vida das pessoas que nelas residem, tem como estratégia expulsar os quilombolas dos territórios por eles ocupados, com o escopo de que tal território seja apropriado por atores que detenham algum tipo de poderio, sobretudo econômico, nas localidades investigadas.

Um último aspecto que merece ser debatido é a perspectiva do racismo, que, no escopo deste trabalho, é também compreendido como um aspecto que isola e torna precária a vida nos territórios quilombolas. Almeida (2019) nos lembra de que o racismo representa uma chaga que é estrutural nas sociedades contemporâneas, ou seja: trata-se de um verdadeiro sistema, entranhado nas relações interpessoais, na composição do Estado e nas próprias políticas públicas, que tem como escopo inferiorizar, desumanizar e explorar as pessoas negras.

Grada Kilomba (2019) salienta que as manifestações de racismo resultam na naturalização da condição de inferioridade dos indivíduos negros, fazendo com que essas pessoas sejam constantemente subalternizadas, exploradas e mortas, sem que tal arranjo de coisas desperte processos sistemáticos de indignação e repulsa por parte da sociedade e do aparato de Estado.

Restou evidente, nos contatos e diálogos com as comunidades quilombolas, as múltiplas formas de racismo que acometem essas pessoas. O próprio muro demasiadamente alto, à esquerda da Figura 1, representa um indicativo de racismo, que revela o desejo de determinados indivíduos de isolar-se da comunidade e, portanto, não manter tipo algum de contato com os quilombolas, que são vistos como fonte de alguma forma de perigo. Tal aspecto ficou evidenciado 
na fala, permeada por dor, indignação e revolta, das pessoas com as quais interagimos no território quilombola de Campos Correa.

Não obstante vale salientar que o indicativo de racismo, por meio dos muros elevados, por parte de sujeitos que residem nas cercanias das comunidades, ficou evidenciado em outros territórios nos quais estivemos; por exemplo, na Comunidade Quilombola de São Benedito/Tia Eva, que fica no perímetro urbano de Campo Grande, o conjunto de residências no entorno da comunidade possui também muros demasiadamente elevados, portões significativamente fechados, além de cerca elétrica e monitoramento por câmera, numa dinâmica em que esse conjunto de tecnologias de vigilância representa uma evidente tentativa racista de evitar maiores contatos com a comunidade quilombola.

Além disso, destaque-se que a recusa do poder público em amparar os territórios quilombolas, negligenciando, por exemplo, a demanda da Comunidade Quilombola de Campos Correa por energia elétrica e água encanada, pode ser compreendida enquanto fonte de racismo institucional para com os quilombolas. Moreira (2019) salienta que o racismo institucional decorre de formas de tratamento diferenciado que pessoas negras podem receber em alguma instituição, seja ela pública, seja ela privada, em função de seu pertencimento racial. Voltando à questão do oferecimento dos serviços de água e luz, parece-nos que tal perspectiva do racismo institucional não pode ser de todo descartada, uma vez que é evidente a falta de interesse e coordenação dos organismos públicos em compreender as particularidades da vida nos quilombos e, desse modo, tratar os quilombolas enquanto cidadãos na plenitude de seus direitos por serviços básicos e, sobretudo, por respeito.

Por fim, vale ainda citar a perspectiva do racismo ambiental, que, segundo Rangel (2016), perfaz o expediente de estimular, de forma proposital, processos de degradação ambiental e poluição em territórios ocupados por populações tradicionais, tais como quilombolas e/ou indígenas. Nesse mesmo sentido, Moutinho-da-Costa (2011) pontua que o racismo ambiental é o conjunto de ações por meio das quais há processos de agressão ao meio ambiente, à cultura e aos modos de vida tradicionais, de tal modo que tais aspectos, em última análise, podem implicar a inviabilização de determinadas formas de vida - tais como a vida nos quilombos, nas aldeias e em áreas peculiares, nas quais o cotidiano gira em torno de elementos que rompem com a lógica eurocêntrica e colonialista. Ressalte-se que a própria omissão do poder público em zelar pelos ativos socioambientais, culturais e patrimoniais de determinadas comunidades, tais como os agrupamentos quilombolas, pode ser encarada como possível prática de racismo ambiental (SILVA, 2012).

Desse modo, vale aqui citar um exemplo paradigmático de possível racismo ambiental em um dos territórios que visitamos: na Comunidade Quilombola Família Osório, que fica na cidade de Corumbá, há um pequeno córrego, conforme é possível ver à esquerda da Figura 2, que "corta" o território e desemboca no Rio Paraguai, o qual, por sua vez, margeia a comunidade. De tempos em tempos, segundo relatos dos moradores, há um forte odor que contamina a comunidade em função de dejetos lançados no córrego, o que, além de causar muito desconforto, é fonte de perigo e de doenças, já que, não raro, os moradores, sobretudo as crianças, acabam entrando em contato com a água do córrego contaminada. 
Figura 2 - Comunidade Quilombola Família Osório (esquerda) e Comunidade Quilombola de Campos Correa (direita)
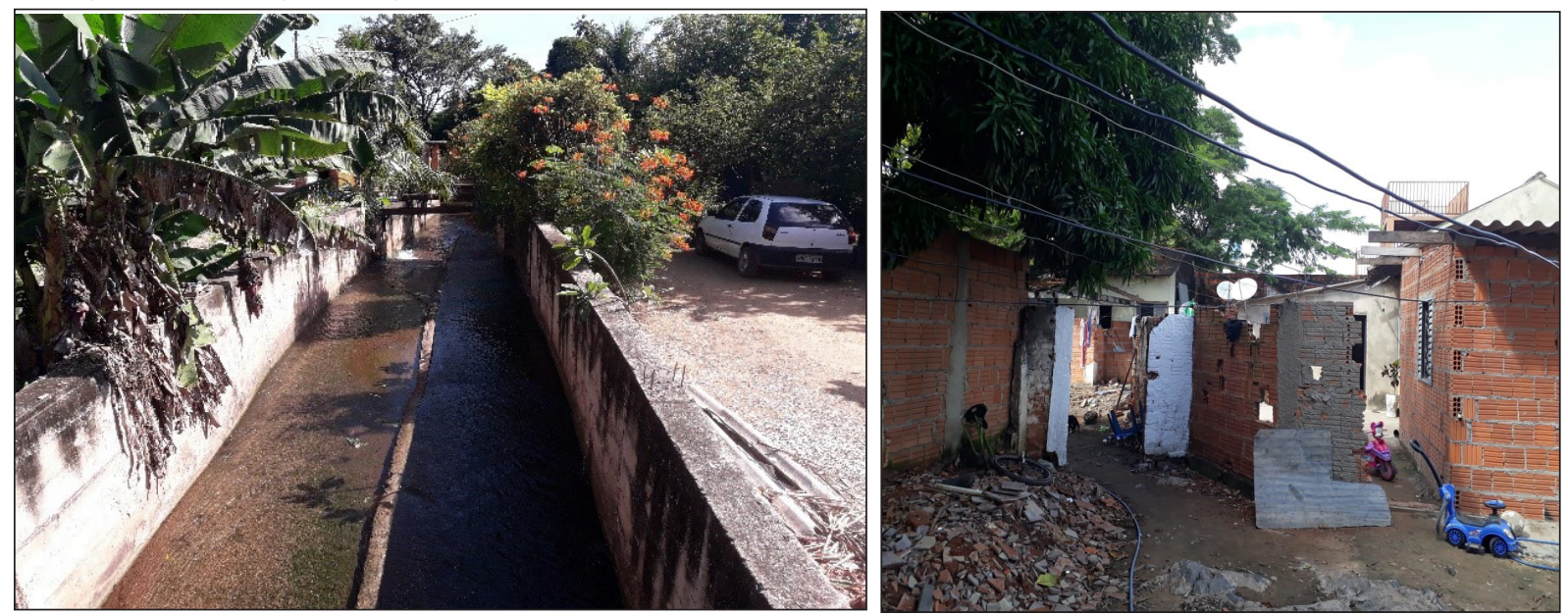

Fonte: Arquivo dos autores, 2020.

Ainda com a pretensão de "desnudar" indicativos de racismo ambiental, que isola e torna difícil a vida nos quilombos, vale reiterar a realidade da Comunidade Quilombola de Campos Correa: ao visitarmos o território em questão, notamos uma quantidade significativa de entulho e lixo cercando as residências, conforme é possível perceber na porção à direita da Figura 2. Não nos pareceu, nos contatos com a comunidade, que há qualquer tipo de esforço, sobretudo por parte das instituições responsáveis pela coleta seletiva em Corumbá, em retirar o lixo da comunidade, ou seja: parece que há uma crença naturalizada de que os territórios quilombolas podem conviver com uma realidade cercada de muita sujeira e poluição, sem que seja ativo o esforço de contribuir com a mudança dessa situação. Ademais, um olhar atento para a Figura 2, à direita, permite com que se vislumbrem muitos fios eletrificados que ligam as residências - tais fios representam os "gatos" de energia elétrica que, conforme já se fez menção anteriormente, são comuns nas comunidades pesquisadas.

Portanto as análises esmiuçadas nos parágrafos anteriores revelam vários indicativos de fatores que fazem com que as comunidades quilombolas estejam isoladas, subsistindo em uma realidade de significativa precariedade. Porém será que o cotidiano de isolamento e precariedade não pode ser, de algum jeito, (re)significado, de forma a permitir novas possibilidades de (re) existência aos quilombolas? No tópico que segue, há um esforço de problematizarmos a questão acima pontuada.

\section{AS TÁTICAS DE EMPODERAMENTO}

Ao longo dos contatos com as comunidades, foi possível perceber um conjunto de táticas de empoderamento que, no geral, resultam em: (a) processos de defesa do território quilombola, com o propósito de proteger a comunidade contra tentativas de expropriação do território; (b) atitudes de pressão, mesmo que ainda incipientes, para que as comunidades sejam amparadas, principalmente pelo conjunto de políticas públicas; e (c) situações de "volta às origens", manifestadas pelo desejos dos quilombolas de permanecer e proteger o território.

Em suma, partimos da perspectiva de que o empoderamento representa a construção de mecanismos (táticas) que façam com que as pessoas e/ou comunidades consigam tomar 
as rédeas de seu destino, de modo a lutarem, não raro, contando com a mediação de agentes externos - tais como o Estado ou os movimentos sociais -, por respeito, cidadania e direitos básicos de (re)existência (GOHN, 2004). Aqui vale frisar que (re)existir é a consequência natural dos processos de empoderamento, que permitem com que a comunidade construa novas narrativas e sociabilidades que façam com que a vida nos quilombos seja possível e desejável.

Foi curioso constatar, ao longo das interações que estabelecemos em campo, que o fato de a Fundação Cultural Palmares passar a reconhecer, legalmente, as comunidades enquanto remanescentes de quilombo representou um primeiro passo para que os quilombolas empreendessem táticas de empoderamento. Mesmo que o processo no âmbito de demarcação e titulação dos territórios quilombolas ainda esteja em curso, deve-se ressaltar que, em razão de a comunidade, stricto sensu, ser legalmente reconhecida como quilombo, foi possível que os quilombolas se protegessem contra processos de especulação e expropriação do território, dado que não mais poderiam ser retirados, por atitudes de ofício e/ou discricionárias, dos territórios que tradicionalmente ocuparam.

O fato de as próprias pessoas que residem nas comunidades passarem a enxergar umas às outras como quilombolas, não obstante, fez com que, paulatinamente, elas buscassem mais detalhes de sua ancestralidade, processo este que reforçou o sentimento de pertença e o senso de comunidade nos territórios, implicando atitudes mais colaborativas e solidárias por parte dos sujeitos aquilombados.

Ademais, constatamos que o expediente de "sentir-se quilombola" implicou processos de valorização da negritude. Tal arranjo, além de fazer com que os sujeitos lidassem melhor com os traços característicos da negritude, tais como a cor da pele ou a condição do cabelo, estimulou, ainda que de modo incipiente, uma consciência da necessidade de se combater o racismo.

Uma história que chamou atenção e que merece vir à tona refere-se ao contexto em que as comunidades de Campos Correa, Família Osório e Maria Theodora - todas elas localizadas em Corumbá - passaram pelos primeiros processos de se compreender como territórios remanescentes de quilombo. Em resumo, o processo de pesquisa historiográfica, organização e estímulo para que tais comunidades passassem a reconhecer a si próprias enquanto territórios quilombolas começou nos idos de 2006, depois que uma jovem mulher sul-mato-grossense e negra foi vítima de racismo no ambiente de trabalho e, ao lutar ativamente pelos direitos que Ihe são pertinentes, fundou o Instituto da Mulher Negra do Pantanal (IMNEGRA), que, entre um conjunto extenso de atribuições, possui a missão de auxiliar nos processos de identificação, catalogação e organização das comunidades remanescentes de quilombo na região do Pantanal de Mato Grosso do Sul.

Nos territórios quilombolas pesquisados, sobretudo naqueles que se localizam em Corumbá, foi perceptível o exemplo de luta que a supracitada mulher, que ainda hoje preside o IMNEGRA, representa para os quilombolas. Os próprios sujeitos pesquisados alegaram se inspirar na presidenta do IMNEGRA, em um processo que, conforme lembra Ribeiro (2019), perfaz uma situação importante para que, a partir dos exemplos emblemáticos de luta e resistência negros, a comunidade negra possa também engajar-se nas reivindicações por cidadania.

Desse modo, os próprios quilombolas, depois de um processo prévio de organização, passaram a interagir de modo mais ativo, por exemplo, com o Ministério Público Federal (MPF), levando a esta instância demandas específicas da comunidade, tais como a luta por água encanada e luz elétrica, e, não raro, denunciando a negligência no atendimento aos direitos básicos da 
população negra e quilombola. Foi interessante o relato de que, muito embora os quilombolas tenham tomado consciência da existência e importância do MPF na defesa dos direitos de povos específicos, foi só depois que tal autarquia passou a ter, no seu quadro funcional, uma procuradora da República também negra que os processos que envolviam as demandas dos quilombolas passaram a tramitar com um pouco mais de celeridade, ainda que sem muitos resultados concretos, à época em que estivemos nos territórios, em 2019.

Portanto os relatos brevemente esmiuçados acima nos fazem lembrar de Ribeiro (2019), que salienta que a representatividade negra nos espaços de poder é crucial para a defesa das demandas dos negros. E é desse modo, inspirando-se e contando com a representatividade negra nos espaços de poder, que os quilombolas, aos poucos, desenvolvem estratégias de empoderamento, pressionando as políticas públicas, mesmo que ainda sem muita força, para que o seu território e seu modo de vida sejam respeitados; e para que os fatores que tornam precária a vida nos quilombos sejam ressignificados.

Foi paradigmático constatar, junto às comunidades pesquisadas, a importância das mulheres negras, que são as principais forças motrizes dos processos de organização e luta por direitos e cidadania aos quilombolas. Nesse sentido, vale citar a intelectual e ativista feminista bell hooks ${ }^{4}$ (2019), que lembra que as mulheres negras, historicamente, foram exemplos de múltiplas (re) existências contra variadas formas de opressão, provenientes sobretudo da raça interseccionada com o marcador do gênero. Ainda, segundo a autora, a sociedade só será mais fraterna e justa quando as mulheres negras, definitivamente, conseguirem ocupar os melhores lugares de poder e de agência nas sociedades contemporâneas, ressignificando séculos de opressão em que, desde sempre, os corpos negros de milhares de mulheres no mundo todo foram explorados, violados e subalternizados.

Para além dos elementos acima problematizados, constatamos ainda que o aspecto cênico dos territórios quilombolas, à ótica dos sujeitos com os quais dialogamos, é algo que faz com que a vida nas comunidades seja um pouco mais aprazível, a despeito dos desafios, isolamento e precariedades existentes - conforme já se analisou anteriormente, neste trabalho. Percebemos que a tomada de consciência quanto à beleza do território, somada ao senso de comunidade decorrente do contexto em que os sujeitos passaram a (re)conhecer uns aos outros enquanto quilombolas, fez com que ocorresse um processo de "volta às origens", de tal modo que, além de impelir os quilombolas a valorizarem a sua própria negritude e história, tal expediente estimulou com que muitos deles ressignificassem o desejo de abandonar a comunidade.

A Figura 3, em suma, ilustra alguns elementos da paisagem e da beleza cênica presentes em dois dos territórios quilombolas sul-mato-grossenses que participaram da pesquisa.

\footnotetext{
${ }^{4}$ bell hooks é o pseudônimo de Gloria Jean Watkins, uma intelectual e ativista afro-americana. A grafia do pseudônimo em letras minúsculas revela uma vontade da autora de não dar ênfase à sua pessoa, mas à potência do conteúdo de sua obra intelectual.
} 
Figura 3 - Mirante da Comunidade Quilombola de Furnas do Dionísio (esquerda) e da Comunidade Quilombola de Furnas dos Baianos (direita)
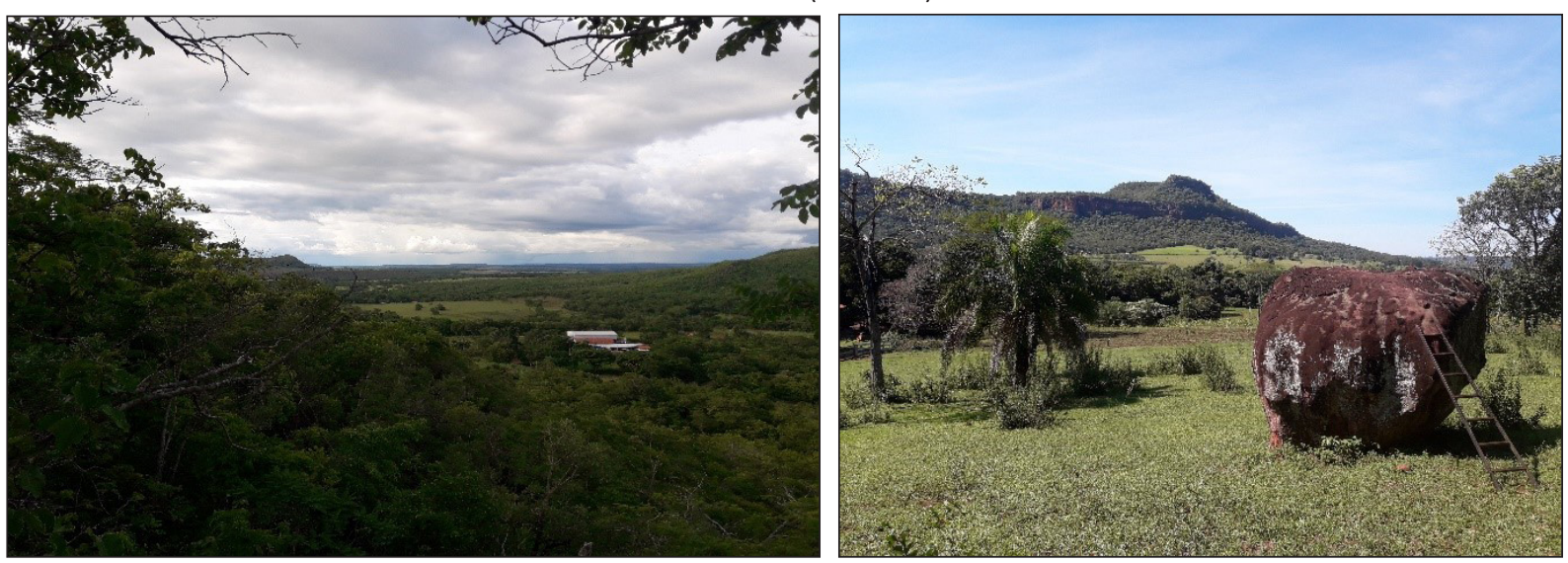

Fonte: Arquivo dos autores, 2020.

Foi curioso perceber, principalmente na fala das pessoas mais jovens, o desejo de permanecer na comunidade e, de alguma forma, empreender algum tipo de atividade que dinamize o território e, portanto, gere alguma forma de desenvolvimento sustentável no espaço em que vivem. Segundo esses mesmos sujeitos, durante muito tempo foi naturalizado o desejo de abandonar a comunidade - o qual foi reforçado no caso dos quilombolas que residem em comunidades que ficam no perímetro rural, cujo acesso é um pouco mais demorado e complexo.

Ao refletirmos sobre o porquê dessa naturalização, no passado recente, do desejo de se abandonar a comunidade, faz-se necessário recorrermos a Fanon (2008), que nos lembra de que o racismo e a ideologia da branquitude impelem os sujeitos negros a empreenderem mecanismos, quase sempre, fontes de muito sacrifício e sofrimento, para que neguem a sua história e o seu modo de vida e, dessa forma, sejam inseridos compulsoriamente em uma lógica capitalista, eurocêntrica e racista, que desde sempre explorou e desumanizou os corpos negros.

Nesse ínterim, depreende-se que é fonte de muitas potencialidades esse "novo olhar", que, de alguma forma, faz com que as pessoas queiram dar sequência a suas vidas nos territórios quilombolas, de onde se originam os aspectos de sua ancestralidade negra. Tal atitude, fonte de esperança de uma verdadeira descolonização da vida nos quilombos, reveste-se de um caráter desafiador e muito intrigante, que - no nosso entender - propõe novas possibilidades de (re) existência nos territórios quilombolas.

Vale frisar, por ser oportuno, que foram muito inspiradoras e interessantes as perspectivas apontadas pelos quilombolas que dão conta do desejo de desenvolver, nos próprios territórios, atividades socioeconômicas que sejam sustentáveis e, nesse sentido, impliquem a geração de renda consubstanciada com a manutenção das especificidades socioambientais e culturais das comunidades. Foram corriqueiras as menções, pelos sujeitos da pesquisa, da possibilidade de que sejam empreendidas atividades ligadas à gastronomia, ao turismo receptivo e à produção agrícola em pequena escala, nos próprios territórios, de modo a fixar as pessoas nas comunidades e permitir com que elas garantam a sua subsistência sem que tenham de se envolver em ocupações degradantes, mal remuneradas e distantes do território no qual residem.

Quanto à gastronomia, foram várias as menções às comidas típicas das comunidades, que se valem de ingredientes peculiares e formas de preparo muito características. É o caso, 
por exemplo, das preparações à base de peixe, nas comunidades de Campos Correa e Família Osório, que se localizam em Corumbá, nas margens do Rio Paraguai; ou mesmo o churrasco, a galinha caipira e o arroz de carreteiro, que são alimentos comuns nas comunidades de Furnas dos Baianos e Furnas do Dionísio. Enfim, vale destacar que esses elementos da gastronomia típica são encarados, pelos próprios quilombolas, como possíveis fontes de renda e subsistência, que podem permitir novos rumos e novas possibilidades aos territórios.

No que tange ao turismo, vale dizer que há um desejo, manifestado pelas comunidades, de recepcionar pessoas nos territórios, seja para que conheçam elementos da história e constituição dos agrupamentos quilombolas, seja para que contemplem a beleza cênica dos territórios e, quem sabe, alimentem-se com as comidas, produzidas a partir dos ingredientes e das formas de preparo típicas nas comunidades. Muito embora se saiba que o turismo pode representar um risco para as comunidades, caso ocorra de forma descoordenada e irrefreada, ainda assim merece destaque o fato de que tal atividade é vista com otimismo e entusiasmo por parte da maioria das comunidades, que consideram que o turismo pode ser um expediente que gere renda e ocupação de forma a não obrigar as pessoas a saírem de seus territórios, seja de forma permanente, seja de forma temporária, em busca de melhores condições de vida e subsistência.

Por fim, deve-se destacar que a produção agrícola em pequena escala perfaz uma prática que, no entender dos sujeitos da pesquisa, é fonte de intensa conexão dos quilombolas com a terra e, por conseguinte, com os elementos de sua história e ancestralidade. Nas comunidades que se localizam no perímetro rural, a agricultura em pequena escala é fonte de alimentos, subsistência e, também, de preservação da cultura e dos modos de vida típicos, desejados pelos sujeitos quilombolas com os quais dialogamos no âmbito da pesquisa e que, atualmente, corporificam as comunidades sul-mato-grossenses.

Portanto o que resta dos parágrafos anteriores é a perspectiva de que se percebe, em uma leitura crítica e descolonizada acerca das comunidades quilombolas, a existência de um conjunto de fatores - principalmente ligados ao senso de comunidade, ao desejo de permanecer no território, à beleza cênica e paisagística dos territórios e às atividades socioeconômicas sustentáveis - que, tomados em conjunto, podem representar novas e múltiplas formas de existir e resistir nos territórios quilombolas.

\section{PROBLEMATIZAÇÕES DERRADEIRAS}

Afinal, quais elementos caracterizam o cotidiano das comunidades quilombolas sul-matogrossenses? A Figura 4 ilustra as principais categorias decorrentes do esforço de sistematização das informações que foram esmiuçadas e problematizadas ao longo do artigo, as quais se originaram das entrevistas e observações participantes nos sete territórios quilombolas de Mato Grosso do Sul que fizeram parte da pesquisa. 
Figura 4 - Síntese das principais categorias analíticas do estudo

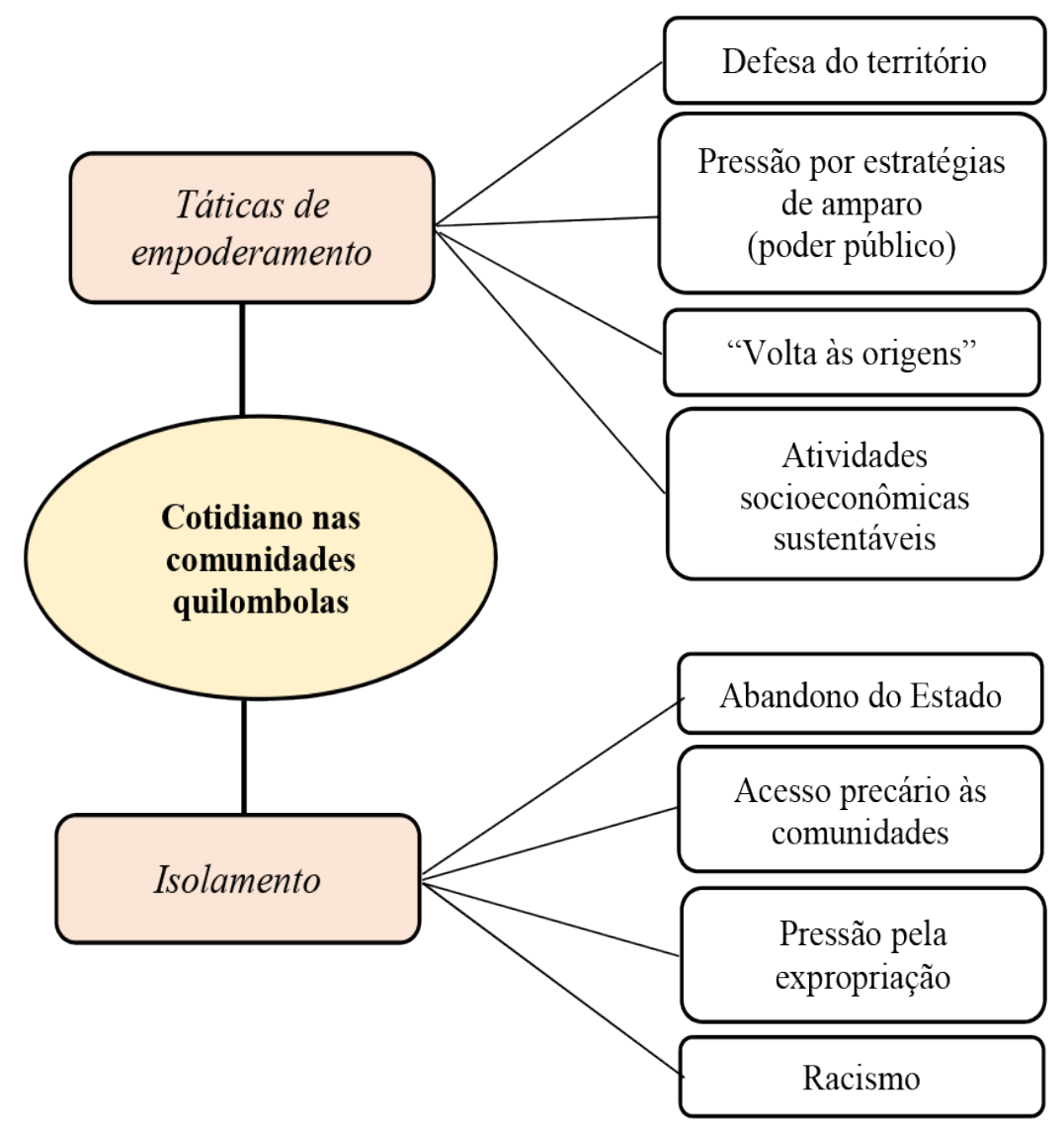

Fonte: Elaborado pelos autores, 2020.

A julgar pelas informações que coletamos em campo, percebemos que as comunidades quilombolas convivem com uma realidade deveras dual: de um lado, tem-se um significativo contexto de isolamento e precariedade da vida, reforçado em muitas circunstâncias pelo próprio aparato do Estado e das políticas públicas; no outro extremo, é perceptível um cenário de múltiplas possibilidades, principalmente ligadas ao senso de comunidade, às táticas de empoderamento, ao desejo de permanecer no território e às atividades socioeconômicas sustentáveis, que podem ser fontes de novas e revigorantes (re)existências no âmbito das comunidades quilombolas.

Vale frisar que as (re)existências, problematizadas ao longo deste texto, são alusivas aos caminhos a partir dos quais a própria comunidade reconhece que pode empreender táticas, não raro com o auxílio dos movimentos da sociedade civil organizada e valendo-se do aparato das políticas públicas que permitem que tais sujeitos permaneçam no território legado pelos seus antepassados, conservando os elementos do próprio território e mantendo as características do modo de vida a que estão habituados. Nesse ínterim, entendemos que as comunidades quilombolas podem - e devem - ser artífices de seu próprio destino, rompendo com a lógica homogeneizante e colonialista que, ainda hoje, objetiva aniquilar esses corpos por intermédio, em muitas circunstâncias, do apagamento de sua história, cultura e modos tradicionais e característicos de vida.

É notório que o presente estudo, com base na pesquisa empírica e nas reflexões que foram conduzidas, pode ensejar processos que, de alguma forma, catalisem as múltiplas potencialidades 
inerentes às comunidades. Entre tais processos de amparo e fomento aos elementos que empoderem os sujeitos aquilombados, é possível destacar os esforços de:

(a) Tornar efetivo o conjunto de políticas públicas destinadas a amparar os territórios quilombolas, com o escopo de que os sujeitos que residem nesses espaços sejam tratados a partir de uma concepção plena de cidadania;

(b) Empreender esforços de se ressignificar e combater as múltiplas dimensões do racismo, seja contra os negros, de um modo geral, seja contra os quilombolas, particularmente; e (c) Estimular a readequação das estruturas de Estado, a fim de que as autarquias públicas não sejam avessas e até mesmo racistas ante as demandas manifestadas pelos quilombolas.

Tal lista de possíveis ações que amparem os sujeitos dos territórios não pretende ser conclusiva: refere-se à meras recomendações e possibilidades, fruto das principais reflexões que foram feitas ao longo do presente estudo.

Por fim, queremos encerrar este artigo reforçando a crença, inspirada nas recomendações de Nascimento (2019), de que é necessário descolonizar os nossos olhares e reflexões que tenham como objeto os elementos do cotidiano dos territórios quilombolas. Tal olhar descolonizado recusa-se a somente realçar a realidade de isolamento e precariedade da vida nos quilombos. Descolonizar os nossos pensamentos implica ir além: trata-se de lançar também o foco nos elementos de potência dos territórios quilombolas; elementos esses que, de alguma forma, permitam com que os sujeitos que habitam esses espaços (re)existam permanentemente.

\section{AGRADECIMENTOS}

O presente trabalho foi realizado com apoio da Fundação Universidade Federal de Mato Grosso do Sul (UFMS/MEC), Brasil; e do Centro Federal de Educação Tecnológica Celso Suckow da Fonseca (CEFET-RJ/MEC), Brasil.

\section{REFERÊNCIAS}

ALLEN, Scott Joseph. Identidades em jogo: negros, índios e a arqueologia da Serra da Barriga. In: ALMEIDA, Luiz Sávio; GALINDO, Marcos; ELIAS, Juliana Lopes (Ed.). Índios do Nordeste: temas e problemas 2. Maceió: EDUFAL, 2000. p. 245-76.

ALMEIDA, Mirianne Santos; MESQUITA, Ilka Miglio. Identidade negra, educação e práticas de resistência: uma leitura decolonial num quilombo urbano. Perspectiva - Revista do Centro de Ciências da Educação, Florianópolis, v. 37, n. 2, p. 480-98, 2019. doi: https://doi.org/10.5007/2175-795X.2019.e52939

ALMEIDA, Silvio Luiz de. Racismo estrutural. São Paulo: Editora Pólen, 2019.

ARRUDA, Dyego de Oliveira; GONÇALVES, Juliano Pessanha. Limites e possibilidades no desenvolvimento de estratégias de turismo de base comunitária em um território quilombola. Interações, Campo Grande, v. 21, n. 1, p. 107-23, 2020. doi: http://dx.doi.org/10.20435/inter.v21i1.1968

BARDIN, Laurence. Análise de Conteúdo. São Paulo: Edições 70, 2011.

BRASIL. Decreto n. 4.887, de 20 de novembro de 2003. Regulamenta o procedimento para identificação, reconhecimento, delimitação, demarcação e titulação das terras ocupadas por remanescentes das comunidades dos quilombos. Brasília-DF, 2003. Disponível em: http://www.planalto.gov.br/ccivil_03/ decreto/2003/D4887.htm. Acesso em: 27 jan. 2020. 
FANON, Frantz. Pele negra, máscaras brancas. Salvador: EDUFBA, 2008.

FIGUEIREDO, André Vieira. Subalternidade e políticas da diferença no Brasil: o caso das comunidades remanescentes de quilombo. Revista Latino-Americana de Direitos Humanos, Belém, v. 6, n. 2, p. 65-78, 2015. doi: http://dx.doi.org/10.18542/hendu.v6i2.3877

FUNARI, Pedro Paulo Abreu; CARVALHO, Aline. O patrimônio em uma perspectiva crítica: o caso do quilombo dos Palmares. Revista Diálogos, Maringá, v. 9, n. 1, p. 33-47, 2005. doi: https://doi.org/10.4025/ dialogos.v9i1.41416

FUNARI, Pedro Paulo Abreu. Heterogeneidade e conflito na interpretação do quilombo dos Palmares. Revista de História Regional, Ponta Grossa, v. 6, n. 1, p. 11-38, 2001.

GOHN, Maria da Glória. Empoderamento e participação da comunidade em políticas sociais. Saúde e Sociedade, São Paulo, v. 13, n. 2, p. 20-31, 2004. doi: http://dx.doi.org/10.1590/\$0104-12902004000200003

HOOKS, Bell. E eu não sou uma mulher? Mulheres negras e feminismo. Rio de Janeiro: Rosa dos Tempos, 2019.

KILOMBA, Grada. Memórias da plantação: episódios de racismo cotidiano. Rio de Janeiro: Editora Cobogó, 2019.

LEITE, IIka Boaventura. Humanidades insurgentes: conflitos e criminalização dos quilombos. In: ALMEIDA, Alfredo Wagner Berno et al. (Org.). Territórios quilombolas e conflitos. Manaus: UEA Edições, 2010. p. 17-40.

MBEMBE, Achille. Crítica da razão negra. 3. ed. São Paulo: N-1 Edições, 2018.

MOREIRA, Adilson José. Racismo recreativo. São Paulo: Editora Pólen, 2019.

MOUTINHO-DA-COSTA, Lara. Territorialidade e racismo ambiental: elementos para se pensar a educação ambiental crítica em unidades de conservação. Pesquisa em Educação Ambiental, Francisco Beltrão, v. 6, n. 1, p. 101-22, 2011. doi: https://doi.org/10.11606/issn.2177-580X.v6i1p101-122

MUNANGA, Kabengele. Origem e histórico do quilombo na África. Revista USP, São Paulo, v. 8, n. 28, p. 56-63, 1996. doi: https://doi.org/10.11606/issn.2316-9036.v0i28p56-63

NASCIMENTO, Abdias. O quilombismo: documentos de uma militância Pan-Africanista. 3. ed. Rio de Janeiro: Ipeafro, 2019.

RANGEL, Tauã. Racismo ambiental às comunidades quilombolas. Revista Interdisciplinar de Direitos Humanos, Bauru, v. 4, n. 2, p. 129-41, 2016.

RIBEIRO, Djamila. Lugar de fala. São Paulo: Editora Pólen, 2019.

SCHMITT, Alessandra; TURATTI, Maria Cecília; CARVALHO, Maria. A atualização do conceito de quilombo: identidade e território nas definições teóricas. Ambiente \& Sociedade, São Paulo, v. 5, n. 10, p. 1-6, 2002. doi: http://dx.doi.org/10.1590/S1414-753X2002000100008

SILVA, Lays Helena Paes. Ambiente e justiça: sobre a utilidade do conceito de racismo ambiental no contexto brasileiro. E-Cadernos CES, Coimbra, v. 17, n. 1, p. 85-111, 2012. doi: https://doi.org/10.4000/eces.1123

SOUZAS, Raquel. Liberdade, violência, racismo e discriminação: narrativas de mulheres negras e quilombolas da mesorregião Centro-Sul da Bahia/Brasil. Revista da ABPN, v. 7, n. 16, p. 89-102, 2015. 
URQUIZA, Antonio; SANTOS, Lourival. Regularização fundiária de comunidades quilombolas em Mato Grosso do Sul. Revista Brasileira de Políticas Públicas, Brasília, v. 7, n. 2, p. 231-47, 2017. doi: http://dx.doi. org/10.5102/rbpp.v7i2.4753

VALENTIM, Renata; TRINDADE, Zeidi Araújo. Modernidade e comunidades tradicionais: memória, identidade e transmissão em território quilombola. Psicologia Política, São Paulo, v. 11, n. 22, p. 295-308, 2011.

WALSH, Catherine. Interculturalidade e decolonialidade do poder: um pensamento e posicionamento "outro" a partir da diferença colonial. Revista Eletrônica da Faculdade de Direito da UFPel, Pelotas, v. 5, n. 1, p. 6-39, 2019. doi: http://dx.doi.org/10.15210/rfdp.v5i1.15002

\section{Sobre os autores:}

Dyego de Oliveira Arruda: Estágio de pós-doutorado no programa de pós-graduação em Administração (PPGAD) pela Universidade Federal de Mato Grosso do Sul (UFMS). Doutorado em Administração de Organizações pela Universidade de São Paulo (USP). Mestrado em Administração pela UFMS. Graduação em Ciências Econômicas pela UFMS. Atualmente, é professor do quadro permanente do Centro Federal de Educação Tecnológica Celso Suckow da Fonseca (CEFET/RJ), lecionando em cursos de graduação e no programa de pós-graduação (nível mestrado acadêmico) em Relações Étnico-Raciais (PPRER). E-mail: dyego.arruda@gmail.com, Orcid: http://orcid.org/0000-0002-9514-284X

Milton Augusto Pasquotto Mariani: Estágio de pós-doutorado pela Faculdade de Economia, Administração e Contabilidade da Universidade de São Paulo (FEA/USP). Doutorado em Geografia Humana pela USP. Mestrado em História Social pela Pontifícia Universidade Católica de São Paulo (PUC/SP). Graduação em Geografia pela Universidade Estadual Paulista Júlio de Mesquita Filho (UNESP). Atualmente, é professor do quadro permanente da Universidade Federal de Mato Grosso do Sul (UFMS), lecionando em cursos de graduação e nos programas de pós-graduação em Administração (PPGAD) e Estudos Fronteiriços (PPGEF). E-mail: miltmari@terra.com.br, Orcid: http://orcid.org/0000-0001-9485-0150

Gabriel Luis Pereira Nolasco: Aluno de doutorado em Psicologia pela Universidade Católica Dom Bosco (UCDB). Mestrado e graduação em Psicologia pela Universidade Federal de Mato Grosso do Sul (UFMS). Atualmente, é integrante do laboratório de Psicologia da Saúde, Políticas da Cognição e da Subjetividade na UCDB. E-mail: nolasco.msn@hotmail.com, Orcid: http://orcid.org/0000-0002-3828-7014

Dayana de Oliveira Arruda: Aluna de doutorado em Educação pela Universidade Federal de Mato Grosso do Sul (UFMS). Mestrado em Educação pela Universidade Federal de Mato Grosso do Sul(UFMS). Graduação em Ciências Sociais pela UFMS. Atualmente, é integrante do Grupo de Estudos e de Investigação Acadêmica nos Referenciais Foucaultianos (GEIARF) na UFMS. E-mail: dayanaarruda@gmail.com, Orcid: http://orcid.org/0000-0001-7002-0363 